OCD. The onset was in adolescence, following which there has been a chronic waxing and waning course, which has interfered with her activities and social function. DSM-IV criteria for OCD require evidence of obsessions or compulsions. In the later case, the repetitive behaviour is driven by obsessions and aimed at preventing or reducing distress, they are time consuming, interfere with normal daily activities and relationships and are not due to psychosis, drugs or general medical conditions. The criteria also state that the person at some time, has recognised that the obsessions or compulsions are excessive or unreasonable, except in the case of children. L meets DSM-IV criteria for a diagnosis of OCD except that, due to her developmental level (as in the case of children), it is not possible to determine with confidence that she understands that the compulsions are excessive. L's presentation also meets the criteria for OCD previously proposed for use in people with learning disabilities. ${ }^{4}$

It is not possible to account for L's presentation by any other diagnosis. In particular, she does not meet criteria for depressive episodes, dementia, psychosis or autism. Compulsions can be a symptom of depressions but $\mathrm{L}$ shows no other depressive symptoms which would be necessary to make the diagnosis. Similarly, compulsions can be a symptom of autism, but L does not meet any recognised criteria for autism (eg. DSM-IV or DCR), as she has no other autistic symptoms. In particular, she shows no evidence of impairment in reciprocal social interaction or empathy (which is described as the 'core' abnormality in autistic spectrum disorders ${ }^{15}$ ), impairment in social (verbal or non-verbal) communication, or onset before the age of three years.

The authors hold the view that OCD may be underdiagnosed amongst people with learning disabilities, due to the inappropriate use of the term 'autistic traits' to refer a person with OCD but no other autistic symptoms. Clearly an identical presentation in a person of average ability would not acquire the label 'autistic traits' or 'autism' in the absence of impairments in reciprocal social interaction and social communication. This view may account for the lack of reported studies of OCD in the field of learning disabilities.

Psychiatric illness is often underdiagnosed in people with learning disabilities, despite most psychiatric illnesses being more common in this population. Often long-standing illness is just accepted or labelled as 'behavioural'. The consequence of this is that carers can feel that they have to change to meet the challenge of caring for the person, with the negative result of denying treatment for the individual. Amongst elderly people, carers may attribute symptoms of psychiatric illness to being part and parcel of old age, rather than potentially treatable illness. Accurate diagnosis is important in order to devise appropriate management plans: management and prognosis differs for different disorders.

Unfortunately, this case highlights the difficulty of treatment of OCD in people with learning disabilities. $\mathrm{L}$ did not respond to pharmacotherapy within her limit of tolerance to the medication. It has also not been possible to apply a successful response prevention programme with her cooperation, or a more simple reward based programme. The difficulty of behavioural treatments of OCD in people with learning disabilities, has been previously described. ${ }^{2}$ However, it is important to attempt treatments as these have sometimes been reported to be successful,' and hence the need for accurate diagnosis.

People with learning disabilities are an ageing popula- tion; rate of increase in lifespan is greater for this group than for the general population. However, at present, there is a poor understanding of the psychiatric needs of this population, due to lack of study. This case contributes to existing knowledge in demonstrating that a wide range of psychiatric illness exists in this population. In the case of $\mathrm{L}, \mathrm{a}$ chronic illness has persisted into her old age, and hence her care needs are considerable. Traditionally, specialist health services for people with learning disabilities in the past had a focus on skill acquisition, development and education. Services need to be planned to accommodate the needs of the growing number of elderly, dependent, chronically ill people with learning disabilities.

Julia Middelton, MB, MRCPsych, MRCGP, Associate Specialist in Learning Disabilities, Northern Community Healthcare NHS Trust, Princess Marina Hospital, UPTON, Northampton NN5 6UH, England.

Sally-Ann Cooper, BSc, MRCPsych,
Consultant in Learning Disabilities Psychiatry,
Rockingham Forest NHS Trust,
St Mary's Hospital,
Kettering,
Northants NN15 7 PW,
England.

References

1. O'Dwyer J, Holme J, Collacott R. Obsessive compulsive disorder in Down's syndrome. J Nerv Ment Dis 1992; 180: 603-4.

2. McNally RJ, Calamari JE. Obsessive compulsive disorder in a mentally retarded woman . Br J Psychiatry 1989; 155: 116-7.

3. Vitiello B, Spreat S, Behar D. Obsessive compulsive disorder in mentally retarded patients. J Nervous Ment Dis 1989; 177: 232-5.

4. Bodfish J, Madison J. Diagnosis and fluoxetine treatment of compulsive behaviour disorder of adults with mental retardation. Am J Ment Retard 1993; 98: $360-7$.

5. Cooper SA. The psychiatry of elderly people with mental handicaps. Int J Geriatric Psychiatry 1992; 7: 865-74.

6. Tait D. Mortality and dementia among ageing defectives. J Ment Def Res 1983; $27: 133-42$.

7. Lund J. Epilepsy and psychiatric disorder in the mental retarded adult. Acta Psychiatrica Scandinavica 1985; 72: 557-62.

8. Patel P, Goldberg D, Moss S. Psychiatric morbidity in older people with moderate and severe learning disabilities, II: the prevalence study. $\mathrm{Br}$ J Psychiatry 1993; 163: 481-91.

9. Sansom DT, Singh I, Jawed SH, Mukherjee T. Elderly people with learning disabilities in hospital: a psychiatric study. J Intellect Disabil Res 1994; 38: 45-52. 10. Cooper SA. High prevalence of dementia amongst people with learning disabilities not attributable to Down's syndrome. Psych Med. In Press.

11. Corbett JA. Psychiatric morbidity and mental retardation. In: James FE, Snaith RP, editors. Psychiatric illness and mental handicap. Gaskell Press, 1979: 11-25.

12. Cooper SA, Collacott RA, Hauck A. Late onset mania in Down's syndrome. J Intellec Disabil Res 1994; 38: 73-8.

13. Day K. Psychiatric disorder in the middle-aged and elderly mentally handicapped. Br J Psychiatry 1985; 147: 660-7.

14. Day KA. The elderly mentally handicapped in hospital: a clinical study. J Ment Def Res 1987; 31:131-46.

15. Wing L. The Autistic continuum. In: Aspects of autism: biological research. Wing L, editor. London: Gaskell Press, 1988: v-viii.

\section{Elderly patients presenting with depressive symptoms}

Sir - Lee \& Lawlor's study ${ }^{1}$ of 100 depressed elderly patients found that those with a diagnosis of major depression had a better outcome than patients with comorbid anxiety/depression and dysthymia. This finding requires further exploration, as the identification of patients at risk 
of chronic illness has important implications for the secondary prevention of depressive disorders.

Keller et $a l$, ' in the 'National Institute of Mental Health Depression Outcome Study', found that the length of illness prior to study entry was the strongest predictor of recovery. More recent naturalistic studies suggest that the duration of illness prior to the commencement of antidepressant treatment may be the most important factor predicting outcome. ${ }^{3,4}$ These findings are consistent with those of Alexopoulos and colleagues that the level of antidepressant treatment received during an episode predicted time to recovery in a group of depressed elderly patients. ${ }^{5}$ Perhaps the crucial difference between the two subgroups in Lee $\&$ Lawlor's study was the intensity of antidepressant treatment received prior to referral to the psychiatric services. Treatment decisions by general practitioners are often based on the strength of presenting symptoms rather than on membership of a particular diagnostic group, so that the initial treatment of patients presenting with mixed anxiety/depression frequently consists of anxiolytics rather than antidepressant medication. ${ }^{6}$

Prospective studies are required to determine if the lower recovery rate in patients with comorbid anxiety/depression and dysthymia is due to the natural course of these illnesses, or, alternatively, reflects a less vigorous approach to the early treatment of such patients in primary care.

Niall Gormley, MB, MRCPsych, Senior Registrar, Outpatients Dept., Maudsley Hospital, Denmark Hill, London SE5 8AZ, England.

\section{References}

1. Lee $H$, Lawlor BA. The outcome of elderly patients presenting with depressive symptoms. Ir J Psych Med 1997; 14(1): 8-12.

2. Keller MB, Shapiro RW, Lavori PW et al. Recovery in major depressive disorder. Arch Gen Psychiatry 1982; 39: 905-10.

3. Scott J, Eccleston D, Boys R. Can we predict the persistence of depression? $\mathrm{Br}$ J Psychiatry 1992; 161:633-7.

4. Gormley N, O'Leary D. Time to remission in major depression. Is there a link between 'no-treatment interval' and outcome? Eur Psychiatry 1996; 11: 290S-1S.

5. Alexopoulo GS, Meyers BS, Young RC et al. Recovery in geriatric depression. Arch Gen Psychiatry 1996; 53: 305-12.

6. Blacker CVR, Clare AW. Depressive disorder in primary care. Br J Psychiatry 1987, 150: 737-51.

\section{Onset of menstruation and soiling in an adolescent girl}

Sir - Estimates of the prevalence of encopresis vary depending on age and the population as well as the operational definition. However, it appears that soiling secondary to chronic constipation is common. Three percent of five year olds entering school soil reducing to $1.5 \%$ by age seven. Rutter identified $1 \%$ of $10-12$ year old boys with soiling, almost always in association with significant behavioural and emotional problems (Rutter, Tizard \& Whitemore, 1970).

Soiling is however often misidentified because of the shame and secrecy surrounding it. This is a report of a teenage girl who developed soiling following the onset of her periods.

Lisa, 13, was referred by her GP to child and family service. Her referral letter reads "...this pathetic looking girl who is very nervous. She has had occasional vomiting and diarrhoea over the past two weeks." Lisa had always been quiet but generally well-adjusted until two months before referral. She began to feel depressed. She was not going our and she became clingy to her mother. She became disinterested in music. She was not eating, was hiding food and losing weight. She used to cry all night, finding it difficult to get off to sleep and waking at $4 \mathrm{am}$ crying in bed. She cried about people not understanding how she felt. She has been dreaming about her grandmother who died eight years ago. During the day, she has been having memory flashbacks of her grandmother to whom she was close. She has a sense of worthlessness, but never contemplated suicide. Her friends at school began to refuse to go to dinner with her. "Dinner time is the worst time, I feel lonely."

She has had diarrhoea (no vomiting) for eight weeks. Her pants were stained and she would need to change her pants about six times a day. She reported having started her periods a few months before her illness began. As she was unprepared for menstruation, she thought her bleeding was due to a serious illness needing hospitalisation. She continued to believe that the periods are "dirty". At interview, she was not self-assured, she was depressed in outlook with reduced emotional reactivity. Her thought content was dominated by desire to gain weight and her not being liked by friends at school.

Diagnosis of 1) Moderate depressive disorder and 2) Encropresis (soiling type due to overflow) were made. The GP was telephoned to advise discontinuation of imodium and prescribe senekot. Lisa was reviewed two weeks later when she reported having moved her bowel, regained her appetite, stopped soiling her pants and she has become very happy and was looking forward to going back to school.

Comments: Lisa presented with depressive episode resulting from soiling which she did not disclose to her GP. Her soiling as in up to $95 \%$ of the cases (Fitzgerald, 1975) was due to chronic constipation and it responded dramatically to laxatives. What is interesting however is the aetiological role of her menstrual periods.

She was unprepared for periods and she thought she had a serious illness when she started. Although dissuaded of this notion, she continued to believe that periods "are dirty". She hated to see blood on the toilet seat and she developed fear of going to the toilet. She did not move her bowel for a long time. The resultant constipation let to overflow and soiling. She became depressed with biological symptoms.

Lisa presents an example of soiling masquerading as some other psychological illness. Direct enquiry into her bowel functioning revealed the real but less forthcoming underlying pathology. An illustration of a common problem that is not uncommonly concealed.

Laofe Oladele Ogundipe, MB, 25 Stokesay Road, Wellington

Telford, TF1 3NX, England. 